\title{
Treatment of Sulphate Rich Process Effluents using Coal Fly Ash
}

\author{
Tumeletso Lekgoba ${ }^{1}$, Freeman Ntuli $^{1{ }^{*}}$, and Bernard Mosweu ${ }^{1}$ \\ ${ }^{1}$ Botswana International University of Science and Technology, Private Bag 16, Palapye, Botswana
}

\begin{abstract}
Coal fly ash obtained from a local power station was used as an adsorbent in the removal of sulphates in an aqueous solution. The coal fly ash was characterised using an x-ray fluorescence (XRF) which revealed that it was class $C$ and sub-bituminous type fly ash, an $\mathrm{x}$ - ray diffractometer (XRD) which revealed the dominance of a large amorphous phase and a Fourier Transform Infrared Spectroscopy (FTIR) which showed the presence of both organic and inorganic functional groups. Adsorbent dosage, contact time, temperature and solution $\mathrm{pH}$ were varied and all the parameters showed a higher uptake of sulphate ions with their increase, except $\mathrm{pH}$ which showed a decreasing uptake. The pseudo second order model showed a better fit for the sorption data with lower error values than the pseudo first order model. The uptake of sulphate ions followed both the Langmuir and the Freundlich isotherm models with $\mathrm{R}_{\mathrm{L}}$ values for the Langmuir within the range $0<R_{L}<1$ and $n$-values for the Freundlich within the range $0<n<10$ showing a favourable sorption for both models. All the thermodynamic parameters $\left(\Delta \mathrm{G}^{\circ}, \Delta \mathrm{H}^{\circ}\right.$ and $\left.\Delta \mathrm{S}^{\circ}\right)$ were positive indicating a non spontaneous, endothermic and a random solid - liquid interface. The process was shown to follow a unimolecular layer approach with chemical adsorption as the dominating mechanism. Generally, coal fly ash showed a higher affinity for sulphates leading to its effective removal.
\end{abstract}

\section{Introduction}

The purification of water is a wide - ranging process intended to obtain characteristics such as colourless, tasteless, odourless, non-corrosive and clear effluent with sufficient quality for human consumption. The threat to water sources is often defined by the presence of nonbiodegradable wastes in water streams such as heavy metal ions, sulphate ion and the acidity of water [1], [2]. Natural waters often contain a concentration of about $10-50 \mathrm{mg} / \mathrm{L}$ of sulphate ions and it is one of the major dissolved components in rain but most industrial wastewater streams are found with elevated levels of sulphate concentrations [3]. Industrial wastewaters with high sulphate concentration include acid mine drainages, textile effluents and tanneries. Sulphate levels greater than 250 $\mathrm{mg} / \mathrm{l}$ cause water to have a salty taste and may also lead to corrosion in pipes and fixtures [4]. The removal of sulphate ions in wastewater is a complex and tedious process because of their high solubility and stability in aqueous solutions and existing technologies have proven inefficient and costly [5]. Remediation technologies that have been used to remove sulphate ions in wastewaters include active neutralisation by lime, limestone biological sulphate removal and alkaline barium calcium desalination process [6]. These liming agents produce a large volume of sludge which requires disposal and the process has proven to be very costly [7] but studies have been conducted in recent years to find alternative ways to remove sulphates in a more cheaper, efficient and environmentally friendly way. One of the wastewater treatment technologies that has gained attention is adsorption which has shown its capability to remove toxic waste from industrial effluents [2].

Activated carbon adsorption has shown a greater potential for sulphate ion removal but the costs associated with its use has led to a search for alternative materials that are cheaper and locally available in recent years. Studies have shown that fly ash was used to control the production of sulphate - rich acid [8] and soil modification [9]. [10] and [11] successfully studied the removal of sulphates from acid mine drainage and acid leachate using fly ash and the research found that the removal was directly proportional to the fly ash $\mathrm{CaO}$ content (free lime content in the fly ash). The free lime in fly ash controls the acid generation from wastes as it releases the alkalinity to neutralise the acidity produced. A study conducted by [12] has shown that fly ash removes about $80-90 \%$ of sulphates when treating a sulphate rich acid mine drainage. This study investigated the feasibility of using coal fly ash as an adsorbent for the treatment of sulphate rich process effluents. It also focused on studying the effects of process parameters, the rate of adsorption of sulphates and the mechanism of sulphate removal by fly ash.

\section{Experimental Methods}

\subsection{Materials and Chemicals}

Fly ash was obtained from a local power station which was used as an adsorbent and analytical grade chemicals obtained from Sigma Aldrich through a local supplier were used to prepare the conditioning agent, synthetic waste water and standards for calibration of Ultraviolet-Visible Spectrophotometer (UV-Vis). The conditioning reagent

* Corresponding author: ntulif@biust.ac.bw 
was prepared by mixing sodium chloride $(\mathrm{NaCl})$, hydrochloric acid $(\mathrm{HCl})$, glycerol and ethanol $\left(\mathrm{C}_{2} \mathrm{H}_{6} \mathrm{O}\right)$ while the synthetic wastewater was prepared from hydrated ferrous sulphate $\left(\mathrm{FeSO}_{4} .7 \mathrm{H}_{2} \mathrm{O}\right)$ and anhydrous sodium sulphate $\left(\mathrm{Na}_{2} \mathrm{SO}_{4}\right)$ was used to prepare the standards. Sodium Hydroxide $(\mathrm{NaOH})$ was used to adjust the solution $\mathrm{pH}$ while $55 \%$ Nitric Acid $\left(\mathrm{HNO}_{3}\right)$ was used to preserve the samples and Barium Chloride $\left(\mathrm{BaCl}_{2}\right)$ was used for sulphate analysis.

\subsection{Instrumentation}

The sulphate ion concentration in the filtrates was measured using a UV-Vis spectrophotometer (Thermo Scientific - Evolution 201) while the $\mathrm{pH}$ of the solution was measured using a Jenco pH 6810 - Handheld $\mathrm{pH} / \mathrm{mV} /$ Temperature meter (calibrated using buffers of $\mathrm{pH}$ 4.12, 6.86 and 9.00). Coal fly ash was characterised before adsorption using an X-ray diffractometer (Brucker D8 advance) for mineralogy, a Fourier Transform Infrared Spectroscopy (Thermo Scientific - Nicolet is10) for functional group identity, and an X-ray Fluorescence (Olympus Delta Premium - 50 kV) for elemental analysis. A thermo-shaker (Thermo Scientific - SHKE 2000 - 1CE) was used for the adsorption studies.

\subsection{Preparation of simulated wastewater and conditioning agent}

A 3000 ppm aqueous sulphate solution was prepared by dissolving $8.68 \mathrm{~g}$ of $\mathrm{FeSO}_{4} .7 \mathrm{H}_{2} \mathrm{O}$ in $1000 \mathrm{~mL}$ of deionised water. The conditioning agent was prepared by perfectly mixing $30 \mathrm{~mL}$ of $32 \mathrm{wt} \%$ concentrated HCL, $300 \mathrm{~mL}$ deionised water, $75 \mathrm{~g} \mathrm{NaCl}$ solution, $100 \mathrm{~mL}$ of $95 \%$ ethanol and $50 \mathrm{~mL}$ glycerol in a beaker.

\subsection{Adsorption (Batch studies)}

Batch adsorption experiments were carried out by studying the effects of contact time, adsorbent dosage, solution $\mathrm{pH}$ and temperature while shaking at a constant speed of 150 rpm. For contact time, 8 samples of synthetic waste water each in a $100 \mathrm{~mL}$ conical flask were contacted with $5 \mathrm{~g}$ of coal fly ash in a thermo-shaker at $25{ }^{\circ} \mathrm{C}$. At each predetermined time interval $(10,20,30,45,60,75,90$ and 120 minutes) the shaker was stopped and the sample was removed and filtered and a drop of $\mathrm{HNO}_{3}$ was added to the filtrate whilst awaiting analysis. For each of adsorbent dosage (varied at 1, 3 and $5 \mathrm{~g} / 100 \mathrm{~mL}$ ) and solution $\mathrm{pH}$ (varied at 2, 4 and 6), 3 samples of the waste water in a 100 $\mathrm{mL}$ solution was used and samples were agitated at a temperature of $25{ }^{\circ} \mathrm{C}$ for a period of 60 minutes. Temperature was studied by repeating the procedure for studying contact time but in this case there were 3 samples which were removed after 20, 40 and 60 minutes of agitation and this was done for 35 and $45^{\circ} \mathrm{C}$ while the concentrations obtained in the study for contact time at 20 , 40 and 60 minutes were used for a temperature of $25^{\circ} \mathrm{C}$. As was done for contact time, the samples were filtered and were preserved using $\mathrm{HNO}_{3}$ while they awaited to be analysed using the UV-Vis method.

\subsection{Analysis of sulphate concentration}

Analysis of the sulphate content was measured using a $\mathrm{UV}-\mathrm{Vis}$ method and $100 \mathrm{~mL}$ of the sample was poured in a $250 \mathrm{~mL}$ conical flask and $5.0 \mathrm{~mL}$ of the conditioning agent was added and the mixture was stirred. As the solution was being stirred, a spoonful of $\mathrm{BaCl}_{2}$ was added to form a barium sulphate turbidity. After stirring for 1 minute, the solution was then poured in an absorbance cell and the turbidity was then measured in a UV-Vis spectrophotometer. The calibration curve was then prepared measuring the absorbance of the prepared sodium sulphate standard solutions.

Removal of the sulphate ions was calculated by;

$$
\text { Removal }(\%)=\frac{\left(C_{o}-C_{t}\right)}{C_{o}} * 100
$$

Adsorption capacity $(\mathrm{mg} / \mathrm{g})$ is calculated by;

$$
q_{t}=\frac{\left(C_{o}-C_{t}\right)}{m} * V
$$

where $C_{o}$ is the initial solution concentration $(\mathrm{mg} / \mathrm{L}), C_{t}$ is the final solution concentration at any time $t$ and $V$ is the volume of the solution $(\mathrm{mL})$ at a given mass $(\mathrm{m})$ of coal fly ash

\section{Discussion of results}

\subsection{Characterisation of fly ash}

\subsubsection{Elemental/Chemical composition (XRF)}

The analysis of the chemical composition was conducted to determine the relative amounts of the elements that are present in fly ash. Table 1 shows that the sum of the three main constituents which are Silica $(31.7 \%)$, Aluminium Oxide $(19.6 \%)$ and Iron Oxide $(15.8 \%)$ is $67.1 \%$ which is within the range of a Class $\mathrm{C}$ fly ash. The composition of Calcium Oxide which was found to be $23.9 \%$ classifies the fly ash as Sub-bituminous. According to [13], Class C fly ash has the sum of silica, aluminium and iron oxides at ranges of $50-70 \%$ while the sub-bituminous fly ash is contains $5-30 \mathrm{wt} \%$ of calcium oxide. The presence in higher proportions of the ions of calcium $\left(\mathrm{Ca}^{2+}\right)$, aluminium $\left(\mathrm{Al}^{3+}\right)$ and iron $\left(\mathrm{Fe}^{3+}\right)$ proposes a higher adsorption capability of the fly ash [14].

Table 1: Chemical composition of coal fly ash

\begin{tabular}{llc}
\hline Element & $\begin{array}{l}\text { Metal } \\
\text { Oxide }\end{array}$ & \% Comp \\
\hline $\mathrm{Si}$-Silicon & $\mathrm{SiO}_{2}$ & 31.7 \\
$\mathrm{Ca}$ - Calcium & $\mathrm{CaO}$ & 23.9 \\
$\mathrm{Al}$ - Aluminium & $\mathrm{Al}_{2} \mathrm{O}_{3}$ & 19.6 \\
$\mathrm{Fe}$ - Iron & $\mathrm{Fe}_{2} \mathrm{O}_{3}$ & 15.8 \\
$\mathrm{~S}$ - Sulphur & $\mathrm{SO}_{3}$ & 5.29 \\
\hline
\end{tabular}




\begin{tabular}{llc}
\hline $\mathrm{P}$ - Phosphorus & $\mathrm{P}_{2} \mathrm{O}_{5}$ & 0.502 \\
$\mathrm{~K}$ - Potassium & $\mathrm{K}_{2} \mathrm{O}_{5}$ & 0.330 \\
$\mathrm{Mn}$ - Manganese & $\mathrm{MnO}$ & 0.203 \\
& & \\
$\mathrm{Ba}$ - Barium & & 0.215 \\
$\mathrm{Sr}$ - Strontium & & 0.172 \\
$\mathrm{Zr}$ - Zirconium & & 0.135 \\
$\mathrm{Cr}$ - Chromium & 0.048 \\
$\mathrm{Cu}$ - Copper & & 0.025 \\
$\mathrm{Ta}$ - Tantalum & & 0.021 \\
$\mathrm{~Pb}-$ Lead & & 0.019 \\
$\mathrm{Y}-$ Yttrium & & 0.016 \\
$\mathrm{Zn}$ - Zinc & & 0.011 \\
$\mathrm{Th}$ - Thorium & & 0.011 \\
$\mathrm{Nb}$ - Niobium & & 0.0069 \\
$\mathrm{Rb}$ - Rubidium & & 0.0042 \\
\hline
\end{tabular}

\subsubsection{Functional Groups (FTIR)}

Vibration of chemical bonds in a molecule are caused by its absorbance of infrared radiation. This infrared active vibrations cause bands that are visible in an infrared spectrum hence the vibrational spectroscopy is used to identify the organic and inorganic functional groups present in a compound. Functional groups (Fig. 1) detected in coal fly ash that could adsorb SO42- ions included a weak alkyne stretch $(-\mathrm{C} \equiv \mathrm{C}-$ ) at a wave number of $2175.43 \mathrm{~cm}-1$, a medium alkane bend $(\mathrm{H}-\mathrm{C}-\mathrm{H})$ or a stretching (in ring) aromatic compound $(\mathrm{C}-\mathrm{C}=\mathrm{C})$ represented by a peak at $1456.07 \mathrm{~cm}-1$, a strong (C-O stretch) for esters and ethers or a variable (C-N stretch) for aliphatic amines at a wave number of $1064.57 \mathrm{~cm}-1$ and an inorganic compound where metals coordinate with halogens $(\mathrm{M}-\mathrm{X}$ stretch where $\mathrm{M}$ is the metal while $\mathrm{X}$ is the halogen) at infrared bands of 433.93 and $206.35 \mathrm{~cm}-1$. According to [14], functional groups are responsible for molecular adsorption due to their chemical reactivity that occurs at the surface of the adsorbent due to Van Der Waal forces. Infrared spectrums are produced in inorganic compounds when covalent bonds are formed within ions [15].

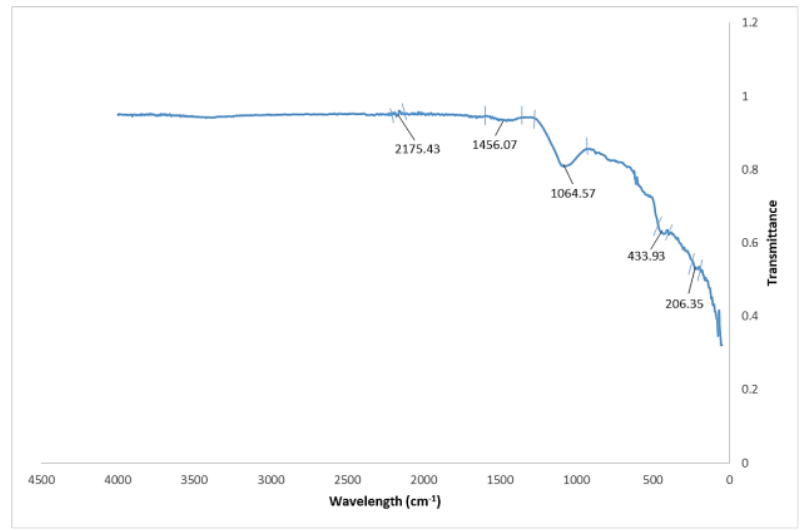

Fig. 1. Functional groups of coal fly ash from FTIR

\subsection{Contact time studies}

The process of adsorption is influenced by the length of time the adsorbent is in contact with the adsorbate. Fig. 2 shows that the adsorption process was very rapid in the first 10 minutes such that it reached a removal of $78 \%$ then a slow uptake was recorded until it reached $98 \%$ in 120 minutes. The rapid uptake in the initial stages of adsorption may be attributed to the higher driving force making the transfer of sulphate ions to the surface of the adsorbent to be fast [16] or the increased concentration gradient between sulphate ions in solution and sulphate ions in fly ash due to availability of a number of vacant sites in the fly ash [17]. The slow uptake for the remaining 110 minutes of the process may be attributed to the slow diffusion of the sulphate ions into the pores of the adsorbent due to the decreased number of available sites leading to a repulsive force between the species in the solution hence the process taking long to reach equilibrium [16], [18].

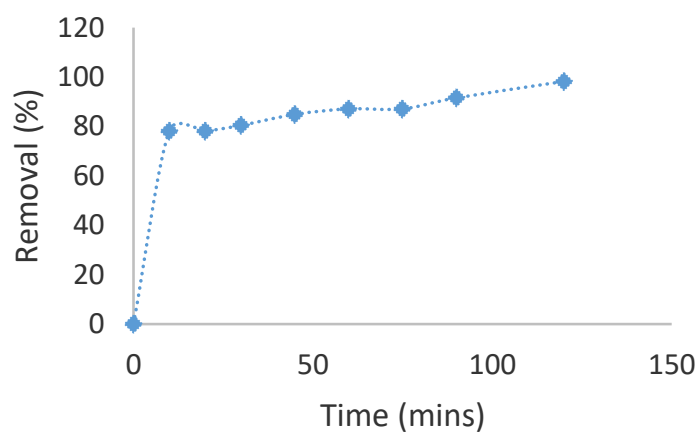

Fig. 2. Effect of contact time on sulphate adsorption

\subsection{Adsorbent dosage}

The capacity of an adsorbent for a given adsorbate concentration is determined by the adsorbent dosage [19]. The removal of sulphate ions from an aqueous solution was evaluated by varying doses from $1-5 \mathrm{~g} / 100 \mathrm{~mL}$ and Fig. 3 shows that the removal increased with an increase in the dosage with $34 \%$ at $1 \mathrm{~g} / 100 \mathrm{~mL}$ and $85 \%$ at $5 \mathrm{~g} / 100$ $\mathrm{mL}$. The increased removal capacity of sulphate ions at higher doses by coal fly ash maybe attributed to increased number of active sorption sites that are available for adsorbent - adsorbate interaction [20] and the greater adsorbent surface area and pore volume that provides more functional groups for the sorption [16].

\subsection{Effect of $\mathrm{pH}$}

$\mathrm{pH}$ is an important factor that causes changes in the surface charge of an adsorbent and determines the predominant mechanism of sorption [20], [21]. The trend of sulphate removal in Fig. 4 shows that there was a decrease in removal capacity of the sulphate ions with an increase in $\mathrm{pH}$ thus at an initial solution $\mathrm{pH}$ of 2 , there was a $98 \%$ removal while at an initial solution $\mathrm{pH}$ of 6 the removal was found to be $74 \%$. The decrease in removal at higher $\mathrm{pH}$ values maybe due to the fact that as the $\mathrm{pH}$ increases 
the surface of the coal fly ash becomes more negatively charged thereby causing increased repulsion between the adsorbate and adsorbent. The repulsion force between the adsorbate and the adsorbent surface is increased when net positive charge decrease with an increasing solution $\mathrm{pH}$ [19].

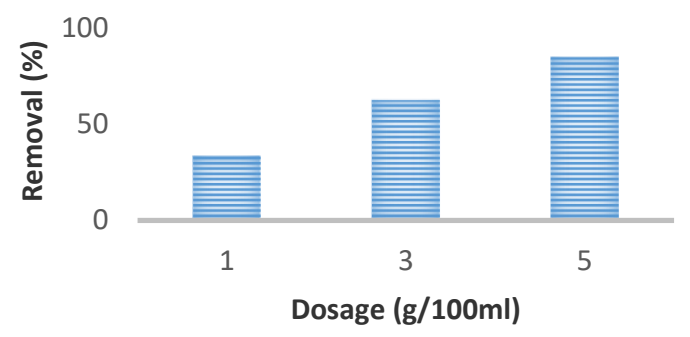

Fig. 3. Effect of adsorbent dosage on sulphate adsorption

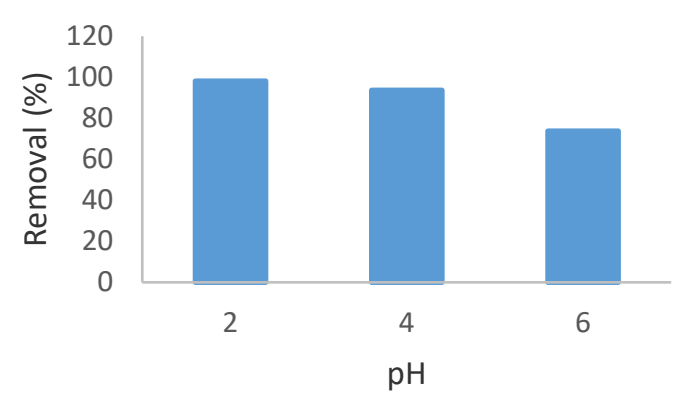

Fig. 4. Effect of $\mathrm{pH}$ on sulphate adsorption

\subsection{Temperature studies}

Temperature is an important parameter in adsorption process because it affects the process in ways being the diffusion rate of adsorbate within the pores of the adsorbent and generation of more adsorption sites due to breaking of the internal bonds by the edge of the adsorbent surface sites [16], [17]. Three (3) temperatures were varied and Fig. 5 presents that the removal of $\mathrm{SO}_{4}{ }^{2-}$ ions increased with a rise in temperature thus the removals were 80,83 and $87 \%$ for 298,308 and $318 \mathrm{~K}$ respectively after 60 minutes of contact. The high removal rates can be attributed to the high kinetic energy of the adsorbate driven by temperature increase making the intermolecular forces between the sorbate and sorbent more strong than that between the sorbate and solution.
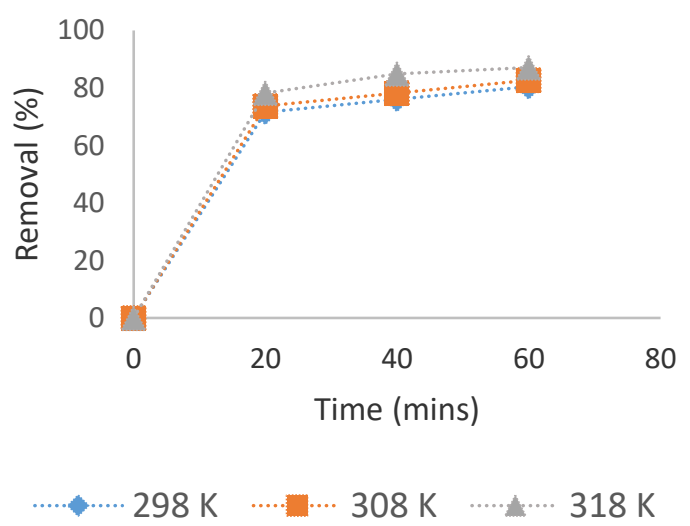

Fig. 5. Effect of temperature on sulphate adsorption

\subsection{Kinetics of adsorption (models)}

Two kinetic models were compared to understand the dynamics and progress of the sorption process with time. The pseudo first and pseudo second order models were used to determine the order and rate of reaction at which the process occurs [18] and the two (2) models are given by equation 3 and 4 respectively.

$$
\begin{gathered}
\log \left(q_{e}-q_{t}\right)=\log q_{e}-\frac{\left(k_{1}\right) t}{2.303} \\
\frac{t}{q_{t}}=\frac{1}{k_{2} q_{e}{ }^{2}}+\frac{t}{q_{e}}
\end{gathered}
$$

Table 2 shows the comparison of the two (2) kinetic models and the first point of interrogation was the coefficient of determination $\left(\mathrm{R}^{2}\right)$ which showed that both models had valued that are greater than 0.99 implying that both models are a better fit to the data. Further interrogation of the models was conducted using the root mean square analysis (RMSE) which was calculated based on the measured and calculated equilibrium adsorption capacities as shown in equation 5 .

$$
R M S E=\Sigma\left(\frac{q_{e, e x p}-q_{e, \text { model }}}{q_{e, \text { model }}}\right)^{2}
$$

The error analysis showed the dominance of the pseudo second order model because lower values of the RMSE were recorded. The dominance of the model over the pseudo first order implies the process follows a chemical adsorption approach which suggests the existence of a chemical bond or electron exchange between the surface of the adsorbent and the adsorbate [14], [22].

The investigation of the rate limiting step was conducted and the calculated values of the intra-particle diffusion models are shown in Table 2 . The linearity of the model is calculated based on equation 6 and the model is followed when a straight line from the plot of $q_{t}$ against $t^{1 / 2}$ passes through the origin with an intercept $I_{D}$ being equal to zero. The values of $I_{D}$ from Table 2 are greater than zero which implies that other rate limiting mechanisms such as film diffusion and external mass transfer are involved in the sorption process.

$$
q_{t}=k_{i d} t^{1 / 2}+I_{D}
$$

\subsection{Kinetics Isotherms}

According to [18], the concentration of the adsorbate in the solution and the amount of adsorbate adsorbed by a specific amount of adsorbent are analysed using the kinetic isotherms. [23] suggested that adsorption isotherms best 
explain the interaction between the adsorbate and the adsorbent thus they are important in optimising the adsorption mechanism pathways, surface property expression and adsorbent capacity together with the Table 3 showing those calculated values.

$$
\frac{C_{e}}{q_{e}}=\frac{1}{K_{L} q_{m}}+\frac{C_{e}}{q_{m}}
$$

where the values of $K_{L}$ and $q_{m}$ are obtained from the plot of $C_{e} / q_{e}$ against $C_{e}$

Table 3, both models show correlation coefficient values that are above 0.99 indicating that both models fit the adsorption data. A further step was taken by calculating the separation factor $\left(R_{L}\right)$ which is calculated based on the equilibrium constant $\left(K_{L}\right)$ and inlet concentration of adsorbate for the Langmuir and the adsorption intensity $(n)$ for the Freundlich model. It was found that both models better fit the data as the separation factors of the different temperatures were found to be in the range $0<R_{L}<1$ implying a favourable nature of adsorption for the Langmuir while the adsorption intensity at the different temperatures was well within the range of $1<n<10$ for the Freundlich also implying a favourable adsorption process [14], [23]. The Langmuir isotherm proposes that the uptake of the adsorbed molecule occurs in a homogenous surface by a monomolecular layer approach with equal affinity towards the sorbate while the Freundlich suggests a monolayer approach accompanied by a heterogeneous energy distribution of active sites in sorbent surfaces[18], [24].

\subsection{Thermodynamic studies}

The chemical and physical adsorptive mechanisms are estimated through the investigation of thermodynamic parameters [25]. The accurate determination of the thermodynamic parameters is dependent on the constant effective design of adsorption systems. The parameters of the two commonly used models, the Langmuir and Freundlich are calculated based on equations 7 and 8 respectively with

$$
\ln q_{e}=\ln K_{f}+\frac{1}{n} \ln C_{e}
$$

where the values of $K_{f}$ and $n$ are obtained from the plot of Inq $q_{e}$ against $\operatorname{InC}_{e}$

\section{As shown in}

that is related to the enthalpy of adsorption $\left(K_{L}\right)$ that is calculated from the Langmuir parameters in equation 6 . The thermodynamic parameters are thus calculated based on equations 9 and 10.

$$
\ln K_{L}=\frac{-\Delta H^{\circ}}{R T}+\frac{\Delta S^{\circ}}{R}
$$

where $\Delta \mathrm{H}^{\circ}$ and $\Delta \mathrm{S}^{\circ}$ are obtained from the plot of $\operatorname{In} K_{L}$ against $1 / T$ and the relationship of $\Delta \mathrm{G}^{\circ}, \Delta \mathrm{H}^{\circ}$ and $\Delta \mathrm{S}^{\circ}$ is given in equation 10 .

$$
\Delta G^{\circ}=\Delta H^{\circ}-T \Delta S^{\circ}
$$

Table 4 presents the calculated thermodynamic parameters and all the parameters were found to be positive. According to [26], a positive Gibbs Free Energy $\left(\Delta \mathrm{G}^{\circ}\right)$ describes a non -spontaneous process indicating it is temperature dependant while [4], [27] assert that the positive values of the enthalpy $\left(\Delta \mathrm{H}^{\circ}\right)$ and entropy $\left(\Delta \mathrm{S}^{\circ}\right)$ changes signify an endothermic process with a higher affinity of coal fly ash for sulphates or a more random solid-liquid interface.

Table 2: Values of the kinetic models

\begin{tabular}{ccccc}
\hline & Temperature (K) & $\mathbf{2 9 8}$ & $\mathbf{3 0 8}$ & $\mathbf{3 1 8}$ \\
\hline & $\mathrm{q}_{\mathrm{e}, \mathrm{model}}(\mathrm{mg} / \mathrm{g})$ & 61.199 & 59.611 & 60.100 \\
Pseudo 1 & $\mathrm{q}_{\mathrm{e}, \mathrm{exp}}(\mathrm{mg} / \mathrm{g})$ & 45.600 & 46.933 & 50.043 \\
Model & $\mathrm{K}_{1}\left(\mathrm{~min}^{-1}\right)$ & 0.0359 & 0.0373 & 0.0392 \\
& $\mathrm{R}^{2}$ & 0.9975 & 0.9963 & 0.9507 \\
& $\mathrm{RMSE}$ & 0.0649 & 0.0452 & 0.0280 \\
\hline \multirow{2}{*}{$\begin{array}{c}\text { Pseudo 2nd Order } \\
\text { Model }\end{array}$} & $\mathrm{q}_{\mathrm{e}, \mathrm{model}}(\mathrm{mg} / \mathrm{g})$ & 52.632 & 52.632 & 55.556 \\
& $\mathrm{q}_{\mathrm{e}, \mathrm{exp}}(\mathrm{mg} / \mathrm{g})$ & 45.600 & 46.933 & 50.044 \\
$\mathrm{k}_{2}(\mathrm{~g} / \mathrm{mg} \cdot \mathrm{min})$ & 0.00425 & 0.00451 & 0.00498 \\
Intra-Particle & $\mathrm{R}$ & 0.9989 & 0.9989 & 1.00 \\
Diffusion & $\mathrm{RMSE}$ & 0.0178 & 0.0117 & 0.0098 \\
\hline
\end{tabular}


Table 3: Values of the Adsorption isotherms

\begin{tabular}{ccccc}
\hline Temperature $(\mathbf{K})$ & & $\mathbf{2 9 8}$ & $\mathbf{3 0 8}$ & $\mathbf{3 1 8}$ \\
\hline \multirow{2}{*}{ Langmuir Isotherm } & $\mathrm{q}_{\mathrm{m}}(\mathrm{mg} / \mathrm{g})$ & 34.48 & 36.63 & 40.65 \\
& $\mathrm{~K}_{\mathrm{L}}\left(\mathrm{L}_{\mathrm{mg}} \mathrm{mg}^{-1}\right)$ & 0.0059 & 0.0072 & 0.0113 \\
& $\mathrm{R}^{2}$ & 0.9989 & 0.9989 & 0.9996 \\
& $\mathrm{R}_{\mathrm{L}}$ & 0.0534 & 0.0443 & 0.0286 \\
\hline \multirow{2}{*}{ Freundlich Isotherm } & $\mathrm{n}$ & 3.212 & 3.654 & 4.796 \\
& $\mathrm{~K}_{\mathrm{f}}$ & 351.99 & 275.28 & 181.51 \\
& $\mathrm{R}^{2}$ & 0.9950 & 0.9943 & 0.9954 \\
\hline
\end{tabular}

Table 4: Values of the Thermodynamic parameters

\begin{tabular}{ccccc}
\hline Temperature $(\mathbf{K})$ & $\mathbf{K}_{\mathbf{L}}$ & $\boldsymbol{\Delta} \mathbf{G}^{\circ}(\mathbf{J} / \mathbf{m o l})$ & $\mathbf{\Delta H}^{\circ}(\mathbf{J} / \mathbf{m o l})$ & $\Delta \mathbf{S}^{\circ}(\mathbf{J} / \mathbf{m o l} . \mathbf{K})$ \\
\hline $\mathbf{2 9 8}$ & 0.0059 & 12823.93 & & \\
$\mathbf{3 0 8}$ & 0.0072 & 12400.74 & 25435.02 & 42.32 \\
$\mathbf{3 1 8}$ & 0.0113 & 11977.55 & & \\
\hline
\end{tabular}

\section{Conclusion}

The feasibility and efficiency of coal fly ash in the uptake of sulphates in process effluents was investigated. The results showed a higher uptake of sulphates with increases in adsorbent dosage, contact time and temperature while a decrease in uptake was recorded with increase in solution $\mathrm{pH}$. The data showed a better fit for the pseudo second order kinetic model and both the Langmuir and Freundlich isotherm models. The process was thermodynamically non -spontaneous, endothermic and showed a higher affinity for sulphates by coal fly ash with increasing randomness at the interface. Generally the process was found to follow a monolayer approach with chemical adsorption as the dominant mechanism.

Future work on the uptake of multi anions (such as $\mathrm{SO}_{4}{ }^{2-}$, $\mathrm{PO}_{4}{ }^{3-}, \mathrm{NO}_{3}{ }^{-1}, \mathrm{Cl}^{-1}$ ) using coal fly ash, treatment of the coal fly ash for adsorptive property enhancement and the use of real waste water is recommended as an expansion of the work.

\section{References}

1. A. [National T. U. of A. Kontopoulos Athens (Greece). Dept. of Mining and Metallurgical Engineering], “Acid mine drainage control," 1998.

2. S. Chiarle, M. Ratto, and M. Rovatti, "Mercury removal from water by ion exchange resins adsorption," Water Res., vol. 34, no. 11, pp. 29712978 (2000)

3. C. Abernathy, D. Cole, M. Cassidy, M. Morris, G. Gomez, and L. Lacker, "Drinking Water Advisory:
Consumer Acceptability Advice and Health Effects Analysis," Epa, 822-R03-007, pp. 1-34 (2003)

4. F. Ntuli, T. Falayi, and M. Mabatho, "A kinetic and thermodynamic study of sulphate removal from AMD using fly ash," Paper presented at 2013 International Conference on Biomedical Engineering and Environmental Engineering., vol. 87, pp. 259 266 (2014)

5. R. Silva, L. Cadorin, and J. Rubio, "Sulphate ions removal from an aqueous solution: I . Coprecipitation with hydrolysed aluminum-bearing salts," Miner. Eng., vol. 23, no. 15, pp. 1220-1226 (2010)

6. J. Mulopo, "Continuous pilot scale assessment of the alkaline barium calcium desalination process for acid mine drainage treatment," J. Environ. Chem. Eng., vol. 3, no. 2, pp. 1295-1302 (2015)

7. D. R. Jenke, G. K. Pagenkopf, and F. E. Diebold, "Chemical changes in concentrated, acidic, metalbearing wastewaters when treated with lime," Environ. Sci. Technol., vol. 17, no. 4, pp. 217-223, (Apr. 1983)

8. S. Seoane and M. C. Leirós, "AcidificationNeutralization Processes in a Lignite Mine Spoil Amended with Fly Ash or Limestone," J. Environ. Qual., vol. 30, no. 4, pp. 1420-1431 (Jan. 2001),

9. H. T. Phung, L. J. Lund, A. L. Page, and G. R. Bradford, "Trace Elements in Fly Ash and Their Release in Water and Treated Soils," J. Environ. Qual., vol. 8, no. 2, pp. 171-175 (Apr. 1979)

10. M. Polat, E. Lederman, I. Pelly, and H. Cohen, "Chemical neutralization of acidic wastes using fly 
ash in Israel," J. Chem. Technol. Biotechnol., vol. 77, no. 3, pp. 377-381 (Mar. 2002)

11. W. M. Gitari, L. F. Petrik, O. Etchebers, D. L. Key, and C. Okujeni, "Utilization of fly ash for treatment of coal mines wastewater: Solubility controls on major inorganic contaminants," Fuel, vol. 87, no. 12, pp. 2450-2462 (2008)

12. M. Gitari, L. Petrik, O. Etchebers, D. Key, E. Iwuoha, and C. Okujeni, "Treatment of acid mine drainage with fly ash: Removal of major contaminants and trace elements," J. Environ. Sci. Heal. - Part A Toxic/Hazardous Subst. Environ. Eng., vol. 41, no. 8, pp. 1729-1747 (2006)

13. A. Ibrahim, "Chemical characterization and mobility of metal species in fly ash - water system," Water Sci., vol. 29, no. 2, pp. 109-122, (2016)

14. T. V. Sima, M. W. Letshwenyo, and L. Lebogang, "Efficiency of waste clinker ash and iron oxide tailings for phosphorus removal from tertiary wastewater: Batch studies," Environ. Technol. Innov., vol. 11, pp. 49-63 (2018)

15. T. S. Malarvizhi and T. Santhi, "Lignite fired fly ash modified by chemical treatment for adsorption of zinc from aqueous solution," Res. Chem. Intermed., vol. 39, no. 6, pp. 2473-2494 (2013)

16. Y. Li, Q. Du, X. Wang, P. Zhang, D. Wang, Z. Wang, and Y. Xia, "Removal of lead from aqueous solution by activated carbon prepared from Enteromorpha prolifera by zinc chloride activation," J. Hazard. Mater., vol. 183, no. 1-3, pp. 583-589 (2010)

17. J. Acharya, J. N. Sahu, C. R. Mohanty, and B. C. Meikap, "Removal of lead ( II ) from wastewater by activated carbon developed from Tamarind wood by zinc chloride activation," Chem. Eng. J., vol. 149, pp. 249-262 (2009)

18. M. Kapur and M. K. Mondal, "Competitive sorption of $\mathrm{Cu}(\mathrm{II})$ and $\mathrm{Ni}(\mathrm{II})$ ions from aqueous solutions: Kinetics, thermodynamics and desorption studies," $J$. Taiwan Inst. Chem. Eng., vol. 45, no. 4, pp. 18031813 (2014)

19. E. Demirbas, N. Dizge, M. T. Sulak, and M. Kobya, "Adsorption kinetics and equilibrium of copper from aqueous solutions using hazelnut shell activated carbon," Chem. Eng. J., vol. 148, no. 2-3, pp. 480487 (2009)

20. W. S. W. Ngah and S. Fatinathan, "Adsorption of $\mathrm{Cu}$ ( II ) ions in aqueous solution using chitosan beads, chitosan - GLA beads and chitosan - alginate beads," Chem. Eng. J., vol. 143, pp. 62-72 (2008)

21. E. Pehlivan and S. Cetin, "Application of Fly Ash and Activated Carbon in the Removal of $\mathrm{Cu} 2+$ and $\mathrm{Ni} 2+$ Ions from Aqueous Solutions," Energy Sources, Part A Recover. Util. Environ. Eff., vol. 30, no. 13, pp. 1153-1165 (2008)

22. S. Mohan and R. Gandhimathi, "Removal of heavy metal ions from municipal solid waste leachate using coal fly ash as an adsorbent," J. Hazard. Mater., vol. 169, pp. 351-359 (2009)
23. K. Y. Foo and B. H. Hameed, "Insights into the modeling of adsorption isotherm systems," Chem. Eng. J., vol. 156, pp. 2-10 (2010)

24. J. Romero-González, J. R. Peralta-Videa, E. Rodríguez, S. L. Ramirez, and J. L. GardeaTorresdey, "Determination of thermodynamic parameters of $\mathrm{Cr}(\mathrm{VI})$ adsorption from aqueous solution onto Agave lechuguilla biomass," J. Chem. Thermodyn., vol. 37, no. 4, pp. 343-347 (2005)

25. H. N. Tran, S.-J. You, and H.-P. Chao, "Thermodynamic parameters of cadmium adsorption onto orange peel calculated from various methods: A comparison study," J. Environ. Chem. Eng., vol. 4, no. 3, pp. 2671-2682, (2016)

26. J. P. Gor, P. N. Shah, and K. Modi, "Physicochemical parameters, isotherms, sorption kinetics and column operations for adsorption of copper ( II ) from wastewater using fly ash," J. Scie \& Ind. Res., vol. 66, no. February, pp. 170-177 (2007)

27. F. Bouhamed, Z. Elouear, and J. Bouzid, "Adsorptive removal of copper ( II ) from aqueous solutions on activated carbon prepared from Tunisian date stones: Equilibrium , kinetics and thermodynamics," J. Taiwan Inst. Chem. Eng., (2012) 